\title{
ANALISIS PREVALENSI DAN FAKTOR PEKERJAAN TERHADAP TERJADINYA GANGGUAN OTOT TULANG RANGKA AKIBAT KERJA PADA PEKERJA PERANCAH DI PT X
}

\author{
Dhani Rinaldi Ardiansyah ${ }^{1}$, Baiduri Widanarko ${ }^{2}$ \\ Magister Keselamatan Dan Kesehatan Kerja, Fakultas Kesehatan Masyarakat, Universitas Indonesia ${ }^{1}$ \\ Departemen Keselamatan Dan Kesehatan Kerja, Fakultas Kesehatan Masyarakat, Universitas \\ Indonesia $^{2}$ \\ dhani.rinaldi@ui.ac.id¹ , baiduri@ui.ac.id²
}

\begin{abstract}
Scaffolding is an inseparable part of a construction work. Scaffolding work contributes to the emergence of risk factors musculoskeletal disorders (MSDs). The purpose of this study was to analyze the risk factors for the occurrence of scaffolding at PT X. This type of research was cross-sectional with 157 employees as respondents of scaffold workers at PT X with data analysis using the chi square test method. Respondents provided information on job characteristics (using Rapid Entire Body Assessment or REBA), complaints of MSDs using the Nordic Body Map questionnaire. This study resulted in the 3 highest prevalence of complaints among workers, namely neck $86.4 \%$, shoulders $82.7 \%$ and hands/wrist $77.8 \%$. This study shows that the risk factors for MSDs of scaffold workers at PT X are type of work OR 8,771 (95\% CI 3,934-19,552), REBA Score OR 2,81 (95\% CI 1,39-5,67). Job adjustments are primarily to lower workers' high REBA scores by minimizing awkward postures, providing carts for transporting materials and hoists to help scaffolding installation.
\end{abstract}

Keywords $\quad$ : Construction, Ergonomic, Msds, Scaffold

\begin{abstract}
ABSTRAK
Perancah merupakan bagian yang tidak dapat dipisahkan dari suatu pekerjaan konstruksi, Pekerjaan perancah berkontribusi pada munculnya faktor risiko gangguan otot tulang rangka akibat kerja (GOTRAK) atau musculoskeletal disorders (MSDs). Tujuan penelitian ini adalah menganalisis faktor risiko terjadinya gotrak pekerja perancah di PT X. Jenis penelitian adalah potong lintang dengan responden pekerja perancah di PT X sebanyak 157 karyawan dengan analisis data menggunakan metode uji chi square. Responden memberikan informasi karakteristik pekerjaan (menggunakan Rapid Entire Body Assesment atau REBA), keluhan gotrak menggunakan kuesioner Nordic Body Map. Penelitian ini menghasilkan 3 prevalensi keluhan tertinggi pada pekerja yaitu leher $86,4 \%$, bahu $82,7 \%$ dan tangan/pergelangan $77,8 \%$. Penelitian ini menunjukkan bahwa faktor risiko terjadinya gotrak pekerja perancah di PT X yaitu jenis pekerjaan OR 8,771 (95\% CI 3,934-19,552), Skor REBA OR 2,81 (95\% CI 1,39-5,67). Penyesuaian pekerjaan terutama untuk menurunkan skor REBA tinggi pada pekerja dengan cara meminimalkan postur janggal, menyediakan gerobak untuk mengangkut material dan katrol untuk membantu instalasi perancah.
\end{abstract}

Kata Kunci : Ergonomi, Gotrak, Konstruksi, Perancah

\section{PENDAHULUAN}

Musculoskeletal Disorders (MSDS) atau gangguan otot tulang rangka akibat kerja (GOTRAK) merupakan permasalahan kesehatan global karena prevalensinya yang tinggi terjadi pada pekerja juga ditambah dengan kurang nya pengetahuan pekerja terhadap gotrak, adapun diantara banyak bahaya kesehatan terkait pekerjaan. Di Amerika Serikat, dilaporkan oleh National Institute for Occupational Safety and Health bahwa sekitar 500.000 pekerja menderita cedera akibat manual handling yang berlebihan per tahunnya (Bridger, 
2003). Kira-kira $60 \%$ dari cedera manual handling terkait dengan lifting (mengangkat) dan 20\% karena pushing (mendorong) atau pulling (menarik). Didapatkan juga data bahwa aktivitas manual handling yang paling sering menyebabkan cedera adalah mengangkat (lifting) dan membawa (carrying) objek yaitu sebesar $61,3 \%$ dan $60 \%$ dari jumlah tersebut menderita cedera/nyeri punggung. Gotrak adalah salah satu masalah kesehatan terpenting dalam industri konstruksi (Neeraja \& Swarochish, 2014), dengan dampak dapat terjadi secara langsung kepada kualitas hidup, beban ekonomi dalam kompensasi, biaya medis, hilangnya upah dan produktivitas (Larsson \& Field, 2002). Prevalensi pekerja konstruksi yang mengalami gotrak berkisar antara 48,5 $76,2 \%$ (Alghadir \& Anwer, 2015; Boschman, van der Molen, Sluiter, \& Frings-Dresen, 2012; Deros et al., 2014). Adapun gotrak itu sendiri mengacu pada kondisi yang melibatkan saraf, tendon, otot, dan struktur pendukung tubuh manusia. Gangguan ini menyebabkan rasa sakit dan penurunan fungsional dan dapat mempengaruhi leher, bahu, siku, lengan bawah, pergelangan tangan dan tangan. Kegiatan proyek konstruksi menjadi hal yang sangat berperan dalam memenuhi kebutuhan industri secara global, banyak dari pekerjaan konstruksi dilakukan dalam kondisi kerja yang buruk.

Pekerjaan konstruksi memiliki keunikan karena lingkup dan lokasinya selalu saja berbeda, dengan waktu yang terbatas, pengerjaan proyek konstruksi ini melibatkan banyak pekerja, berbagai jenis material, alat, dan lokasi yang bervariasi bahkan cenderung berbahaya (bekerja di ketinggian, tempat tertutup, bawah tanah, dan lain-lain).Tuntutan pekerjaan fisik yang berat dan kelelahan yang timbul dari kondisi kesehatan yang buruk dapat meningkatkan risiko kesehatan di antara pekerja konstruksi (Cook, Rosecrance, \& Zimmermann, 1996). Sebagian besar pekerjaan konstruksi menuntut secara fisik dan para pekerja sering kali menunjukkan bahwa mereka kelelahan secara fisik di penghujung hari. Sejumlah faktor terlibat dalam terjadinya gangguan muskuloskeletal yang berhubungan dengan pekerjaan (Punnett \& Wegman, 2004), dengan tingginya tuntutan pekerjaan pada pekerja konstruksi, maka sejalan dengan tingkat prevalensi gotrak yang tinggi ditemukan di antara pekerja konstruksi (Hildebrandt, 1995; Ueno, Hisanaga, Jonai, Shibata, \& Kamijima, 1999; Xu, Bach, \& Ørhede, 1996).

Tujuan dari penelitian ini adalah menganalisis faktor pekerjaan dan skor REBA terjadinya gotrak pada pekerja perancah di PT X. Aptel, Aublet-Cuvelier, and Cnockaert (2002) menyebutkan bahwa pekerjaan merupakan salah satu faktor yang dapat meningkatkan timbulnya gotrak pada pekerja karena pekerjaan membutuhkan kekuatan fisik untuk melakukan pekerjaan dan ini berhubungan dengan kapasitas otot pada tubuh pekerja serta kerja dari ini tentu bergantung pada jenis pekerjaan yang dilakukan. Ada 2 tipe pekerjaan yaitu pekerjaan statis dan pekerjaan dinamis yang masing-masing memberikan risiko ergonomi untuk tiap tiap tersebut(Nunes. \& Bush, 2012).

\section{METODE}

Penelitian ini adalah penelitian potong lintang yang dilakukan selama bulan April - Juni 2021. Responden penelitian ini adalah seluruh pekerja perancah PT $\mathrm{X}$ di Kota Cilegon, Provinsi Banten, sebanyak 157 pekerja diamati dengan menggunakan form REBA dengan melihat postur janggal dan tidak janggal, durasi $\leq 1$ menit dan $>1$ menit, frekuensi $>4 \mathrm{x}$ semenit $\leq 4 \mathrm{x}$ semenit dan beban $>5 \mathrm{~kg}$ dan $\leq 5 \mathrm{~kg}$, setelah itu di tabulasi ke dalam REBA untuk mengetahui skor REBA nya, serta keluhan gotrak yang dirasakan selama 12 bulan terakhir melalui kuesioner yang diisi secara mandiri. menggunakan instrumen Nordic Musculoskelatal Questionnaire (Kuorinka et al., 1987) . Data dianalisis dengan 
analisis bivariat, dengan metode uji statistik analitik dengan uji chi square dilakukan untuk menentukan faktor risiko terjadi nya gotrak dengan variabel bebas yaitu jenis pekerjaan dan skor REBA. Semua analisis dilakukan menggunakan software microsoft excel dan SPSS.

\section{HASIL}

Tabel 1 Hasil pengisian kuesioner mendapatkan hasil bahwa keluhan para pekerja cukup beragam dan tersebar di seluruh bagian tubuh. Keluhan bagian tubuh yang paling banyak antara lain leher $70(86,4 \%)$ responden, yang kedua keluhan terbanyak pada bahu $67(82,7 \%)$ responden dan yang ketiga tangan/pergelangan 63 $(77,8 \%)$ responden, sedangkan keluhan para pekerja non perancah cukup beragam dan tersebar di seluruh bagian tubuh Keluhan bagian tubuh yang paling banyak antara lain punggung bawah $25(32,9 \%)$ responden, yang kedua paha $22(28,9 \%)$ responden, ketiga bahu dengan $21(27,6 \%)$.

Tabel 1. Prevalensi GOTRAK

\begin{tabular}{lcccc}
\hline \multirow{2}{*}{\multicolumn{1}{c}{ Keluhan }} & \multicolumn{3}{c}{\begin{tabular}{c} 
Non \\
\multicolumn{1}{c}{ Perancah }
\end{tabular}} & \multicolumn{2}{c}{ Perancah } \\
\cline { 2 - 5 } Leher & $\mathrm{n}$ & $\%$ & $\mathrm{n}$ & $\%$ \\
Bahu & 70 & $86,4 \%$ & 20 & $26,3 \%$ \\
Punggung Atas & 67 & $82,7 \%$ & 21 & $27,6 \%$ \\
Siku & 36 & $44,4 \%$ & 13 & $17,1 \%$ \\
Tangan/Pergelangan & 63 & $77,8 \%$ & 18 & $23,7 \%$ \\
Punggung Bawah & 42 & $51,9 \%$ & 25 & $32,9 \%$ \\
Paha & 50 & $61,7 \%$ & 22 & $28,9 \%$ \\
Lutut & 23 & $28,4 \%$ & 15 & $19,7 \%$ \\
Kaki/Pergelangan & 33 & $40,7 \%$ & 11 & $14,5 \%$ \\
\hline
\end{tabular}

Tabel menunjukkan bahwa semua pekerja mengalami postur janggal saat bekerja diketahui bahwa sebanyak 81 orang (100\%) pekerja mengalami postur janggal saat bekerja, sebanyak 61 orang $(75,31 \%)$ pekerja memiliki durasi saat kerja di bawah 1 menit dan 20 orang $(24,69 \%)$ memiliki durasi saat kerja di atas 1 menit, sebanyak 54 orang $(66,67 \%)$ pekerja memiliki frekuensi saat kerja di atas 4 kali 1 menit dan 27 orang $(33,33 \%)$ memiliki frekuensi saat kerja di bawah 4x 1 menit, sebanyak 73 orang $(90,12 \%)$ pekerja memiliki beban saat kerja di atas $5 \mathrm{~kg}$ dan 8 orang $(9,88 \%)$ memiliki beban saat kerja di bawah $5 \mathrm{~kg}$, skor REBA tinggi $57(70,6 \%)$ dan rendah $24(29,4 \%)$. Untuk pekerja non perancah diketahui bahwa 52 orang $(64,2 \%)$ pekerja mengalami postur janggal saat bekerja dan 24 orang $(35,8 \%)$ memiliki durasi saat kerja di atas 1 menit, sebanyak 51 orang $(62,96 \%)$ pekerja memiliki durasi saat kerja di bawah 1 menit dan 25 orang $(37,04 \%)$ memiliki durasi saat kerja di atas 1 menit, sedangkan non perancah sebanyak 4 orang $(4,94 \%)$ pekerja memiliki frekuensi saat kerja di atas 4 kali 1 menit dan 72 orang $(95,06 \%)$ memiliki frekuensi saat kerja di bawah 4x 1 menit, sedangkan non perancah diketahui bahwa sebanyak 4 orang $(4,94 \%)$ pekerja memiliki beban saat kerja di atas $5 \mathrm{~kg}$ dan 72 orang $(86,06 \%)$ memiliki beban saat kerja di bawah $5 \mathrm{~kg}$ serta skor REBA tinggi $47(62,25 \%)$ dan rendah $27(37,75 \%)$.

Tabel 2. Faktor Pekerjaan

\begin{tabular}{lcccc}
\hline \multirow{2}{*}{ Variabel } & \multicolumn{2}{c}{ Perancah } & \multicolumn{2}{c}{$\begin{array}{c}\text { Non } \\
\text { Perancah }\end{array}$} \\
\cline { 2 - 5 } Postur & & $\mathrm{n}$ & $\mathrm{n}$ & $\%$ \\
& & 100,00 & & \\
Janggal & 81 & $\%$ & 52 & $64,20 \%$ \\
Tidak & 0 & $0,00 \%$ & 24 & $35,80 \%$ \\
Durasi & & & & \\
$\leq 1$ Menit & 61 & $75,31 \%$ & 51 & $62,96 \%$ \\
$>1$ Menit & 20 & $24,69 \%$ & 25 & $37,04 \%$ \\
Frekuensi & & & & \\
$>4 \mathrm{x}$ & 54 & $66,67 \%$ & 4 & $4,94 \%$ \\
Semenit & & & & \\
$\leq 4 \mathrm{x}$ & 27 & $33,33 \%$ & 72 & $95,06 \%$ \\
Semenit & & & & \\
Beban & & & & $4,94 \%$ \\
$>5 \mathrm{~kg}$ & 73 & $90,12 \%$ & 4 & $45,06 \%$ \\
$\leq 5 \mathrm{~kg}$ & 8 & $9,88 \%$ & 72 & $95 \%$ \\
Skor & & & & \\
REBA & & & & \\
Tinggi & 57 & $70,6 \%$ & 47 & $62,25 \%$ \\
Rendah & 24 & $29,4 \%$ & 27 & $37,75 \%$ \\
\hline
\end{tabular}

Tabel 3 menunjukkan hasil Analisis hubungan antara jenis pekerjaan dengan 
Gotrak. penelitian ini menunjukkan bahwa responden dengan jenis pekerjaan perancah mengalami Gotrak sebanyak 45,22\% dan $6,37 \%$ tidak mengalami Gotrak. Sedangkan untuk responden dengan jenis pekerjaan non perancah mengalami Gotrak sebanyak $21,66 \%$ dan $26,75 \%$ tidak mengalami Gotrak. Hasil uji statistik diperoleh nilai $\mathrm{p}$ value $=0,000$, hal ini menunjukkan bahwa terdapat pengaruh yang signifikan antara jenis pekerjaan dan Gotrak. Responden dengan jenis pekerjaan perancah mempunyai kemungkinan peluang 8,771 (3,934-19,552) kali meningkatkan risiko timbulnya GOTRAK dibandingkan dengan responden yang memiliki jenis pekerjaan non perancah.
Hasil Analisis hubungan antara skor REBA dengan Gotrak diketahui pada penelitian ini bahwa responden dengan jenis skor tinggi mengalami Gotrak sebanyak $39,5 \%$ dan $11,46 \%$ tidak mengalami Gotrak. Sedangkan untuk responden dengan skor rendah mengalami Gotrak sebanyak $12,74 \%$ dan $36,3 \%$ tidak mengalami Gotrak. Hasil uji statistik diperoleh nilai $\mathrm{p}$ value $=0,004$, hal ini menunjukkan bahwa terdapat pengaruh yang signifikan antara skor REBA dan Gotrak. Responden dengan skor REBA tinggi mempunyai kemungkinan peluang 2,81 (1,39-5,67) kali meningkatkan risiko timbulnya gotrak dibandingkan dengan responden yang memiliki skor REBA rendah.

Tabel 3. Faktor Pekerjaan Terhadap Gotrak

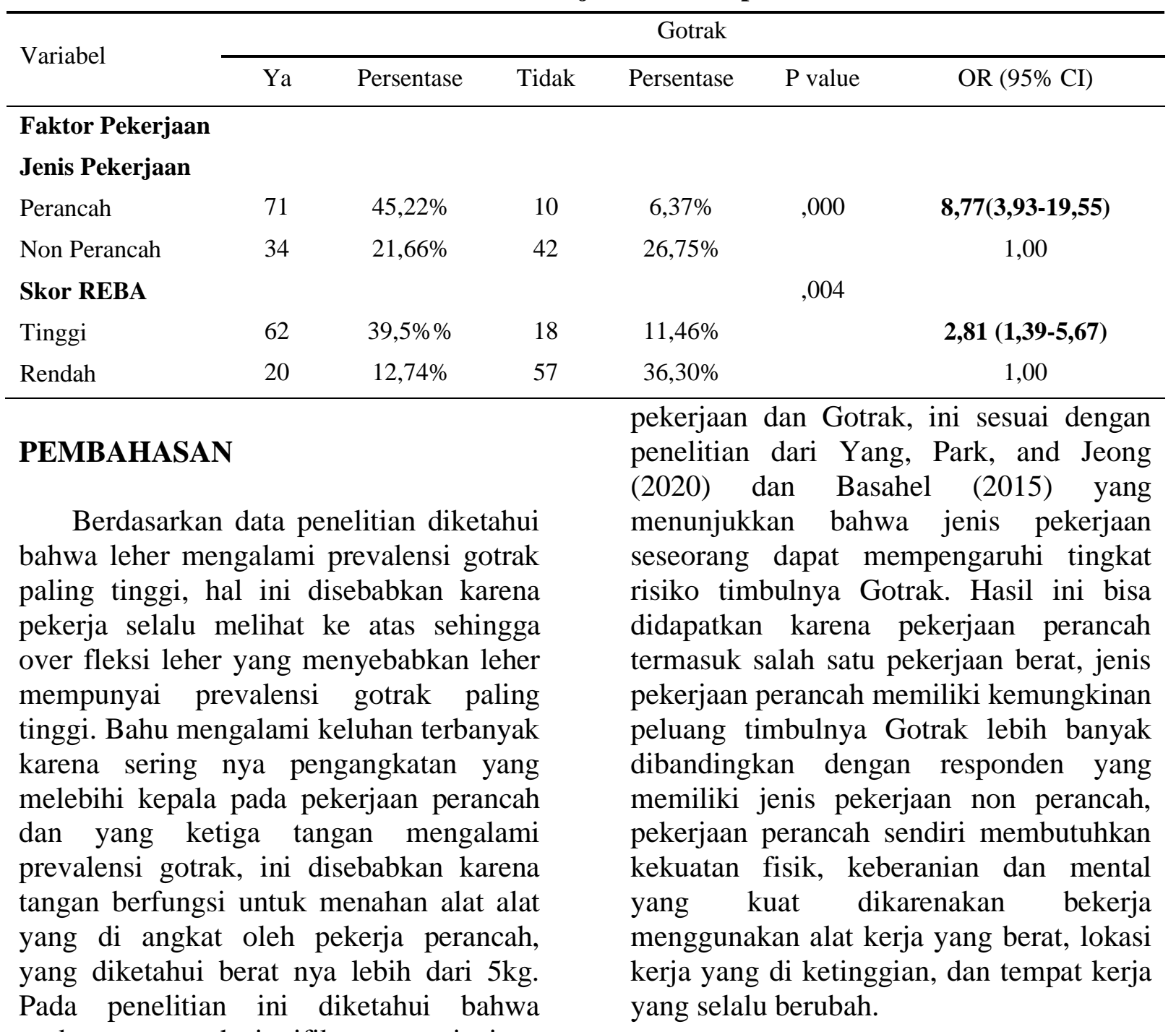
terdapat pengaruh signifikan antara jenis 
Hasil keluhan gotrak pada pekerja non perancah dengan keluhan tertinggi yaitu punggung bawah ini dikarenakan sering nya pengangkatan material dan posisi kerja yang tidak natural oleh pekerja, yang kedua paha dikarenakan posisi kerja yang sering jongkok dan juga base kerja yang tidak stabil, ketiga bahu karena penggunaan force yang berlebihan dan sering pada pekerja. Penelitian ini didapatkan bahwa terdapat hubungan signifikan antara skor REBA dan timbulnya Gotrak. Ini sesuai dengan penelitian dari Nuryaningtyas and Martiana (2014), Dewi (2019), Attar (2014), Wahyuni (2018), Nino, Widjasena, and Ekawati (2019) dan Mozafari, Vahedian, Mohebi, and Najafi (2015)_yang menyebutkan bahwa terdapat hubungan yang signifikan antara skor REBA dengan keluhan gotrak, dikarenakan pekerja perancah banyak melakukan postur kerja yang tidak natural seperti jongkok, membungkuk, melihat ke atas juga durasi kerja, frekuensi kerja dan beban kerja yang tinggi.

\section{KESIMPULAN}

Gambaran dari 157 orang responden dengan 3 keluhan tertinggi yaitu, pada pekerja perancah yaitu leher $86,4 \%$ responden, yang kedua keluhan terbanyak pada bahu $82,7 \%$ responden dan yang ketiga tangan/pergelangan $77,8 \%$ responden, sedangkan untuk pekerja non perancah hasil pengisian kuesioner mendapatkan hasil bahwa keluhan bagian tubuh yang paling banyak yaitu punggung bawah 32,9\% responden, yang kedua paha $28,9 \%$ responden, ketiga bahu dengan $27,6 \%$ responden. Faktor pekerjaan yang berhubungan signifikan terhadap terjadinya gotrak adalah jenis pekerjaan perancah dan skor REBA tinggi. Menurunkan skor REBA tinggi pada pekerja dengan cara meminimalkan postur janggal, menyediakan gerobak untuk mengangkut material dan katrol untuk membantu instalasi perancah.

\section{UCAPAN TERIMA KASIH}

Penulis mengucapkan terima kasih kepada perusahaan yang telah memberi izin peneliti, serta kepada seluruh responden dalam penelitian ini yang telah memberi kesempatan dan waktunya agar peneliti bisa menyelesaikan penelitian ini.

\section{DAFTAR PUSTAKA}

Alghadir, A., \& Anwer, S. (2015). Prevalence of musculoskeletal pain in construction workers in Saudi Arabia. ScientificWorldJournal, 2015 , 529873. doi: $10.1155 / 2015 / 529873$

Aptel, M., Aublet-Cuvelier, A., \& Cnockaert, J. C. (2002). Workrelated musculoskeletal disorders of the upper limb. Joint bone spine, 69(6), 546-555.

Attar, S. M. (2014). Frequency and risk factors of musculoskeletal pain in nurses at a tertiary centre in Jeddah, Saudi Arabia: a cross sectional study. BMC research notes, 7(1),1-6.

Basahel, A. M. (2015). Investigation of work-related musculoskeletal disorders (MSDs) in warehouse workers in Saudi Arabia. Procedia Manufacturing, 3, 4643-4649.

Boschman, J. S., van der Molen, H. F., Sluiter, J. K., \& Frings-Dresen, M. H. (2012). Musculoskeletal disorders among construction workers: a oneyear follow-up study. $B M C$ musculoskeletal disorders, 13(1), 110.

Bridger, R. (2003). Introduction to Ergonomics (2nd ed.). London: Taylor \& Francis Inc.

Cook, T. M., Rosecrance, J. C., \& Zimmermann, C. L. (1996). The University of Iowa: Construction Survey: Biomechnics and Ergonomics Facility, University of Iowa.

Deros, B. M., Daruis, D. D., Khamis, N. K., Mohamad, D., Daud, S. F. M., 
Amdan, S. M., . . . Jamal, N. (2014). Prevalence of Work Related Musculoskeletal Disorders Symptoms among Construction Workers: a Case Study in Malaysia. Iranian Journal of Public Health, 43(Supple 3), 53-57.

Dewi, N. F. (2019). Risiko Musculoskeletal Disorders (MSDs) pada Perawat Instalasi Gawat Darurat (IGD). Jurnal Vokasi Indonesia, 7(2), 39-48.

Hildebrandt, V. H. (1995). Back pain in the working population: prevalence rates in Dutch trades and professions. Ergonomics, 38(6), 1283-1298.

Kuorinka, I., Jonsson, B., Kilbom, A., Vinterberg, H., Biering-Sørensen, F., Andersson, G., \& Jørgensen, K. (1987). Standardised Nordic questionnaires for the analysis of musculoskeletal symptoms. Applied ergonomics, 18(3), 233-237.

Larsson, T. J., \& Field, B. (2002). The distribution of occupational injury risks in the Victorian construction industry. Safety Science, 40(5), 439456.

Mozafari, A., Vahedian, M., Mohebi, S., \& Najafi, M. (2015). Work-related musculoskeletal disorders in truck drivers and official workers. Acta Medica Iranica, 53(7), 432-438.

Neeraja, T., \& Swarochish, C. (2014). The factors associated with MSDs among construction workers. Journal of human ergology, 43(1), 1-8.

Nino, B. P., Widjasena, B., \& Ekawati, E. (2019). Hubungan tingkat risiko ergonomi dan beban angkut terhadap keluhan musculoskeletal disorders (msds) pada pabrik pemotongan kayu x mranggen, demak. Jurnal Kesehatan Masyarakat (e-Journal), 6(5), 494-501.
Nunes., I. L., \& Bush, P. M. (2012). WorkRelated Musculoskeletal Disorders Assessment and Prevention. Appl Ergon(6), 459.

Nuryaningtyas, B. M., \& Martiana, T. (2014). Analisis Tingkat Risiko Muskuloskeletal Disorders (MSDs) dengan The Rapid Upper Limbs Assessment (RULA) dan Karakteristik Individu Terhadap Keluhan MSDs. The Indonesian Journal of Occupational Safety and Health, 3(3), 160-169.

Punnett, L., \& Wegman, D. H. (2004). Work-related musculoskeletal disorders: the epidemiologic evidence and the debate. Journal of electromyography and kinesiology, 14(1), 13-23.

Ueno, S., Hisanaga, N., Jonai, H., Shibata, E., \& Kamijima, M. (1999). Association between musculoskeletal pain in Japanese construction workers and job, age, alcohol consumption, and smoking. Industrial health, 37(4), 449-456.

Wahyuni, S. (2018). Faktor-faktor yang berhubungan dengan keluhan subyektif musculoskeletal disorders (msds) pada pekerja pembuat bakso (Studi Pada Pekerja Pembuat Bakso Kelurahan Gayamsari Kota Semarang). Universitas Muhammadiyah Semarang,

Xu, Y., Bach, E., \& Ørhede, E. (1996). Occupation and risk for the occurrence of low-back pain (LBP) in Danish employees. Occupational medicine, 46(2), 131-136.

Yang, S. T., Park, M. H., \& Jeong, B. Y. (2020). Types of manual materials handling (MMH) and occupational incidents and musculoskeletal disorders (MSDs) in motor vehicle parts manufacturing (MVPM) industry. International Journal of Industrial Ergonomics, 77, 102954. 